\title{
Joan Estelrich a Galícia. Els contactes peninsulars de la mà dreta de Francesc Cambó
}

\author{
Jesús REVELLES ESQUIROL \\ (UIB) \\ jesusrevelles@gmail.com \\ Recibido: marzo de 2014. Aceptado: abril de 2014.
}

Resum: A les primeres dècades del segle xx es publiquen revistes on coexistien les diferents llengües peninsulars. És el cas, per exemple, de La Gaceta Literaria, en què era ben habitual llegir articles en català i en portuguès. Aquestes publicacions multilingües coincidiren amb l'edat d'or del periodisme gallec i mantingueren l'iberisme com a nou paradigma territorial i, sobretot, cultural, a partir del qual assentar una nova Espanya. Una utopia territorial, cultural i lingüística que comportà un seguit d'articles creuats entre les diferents nacions peninsulars. En aquest sentit, en l'article que presentem veurem com, des de la Lliga Regionalista, s'intervingué en la premsa i en la cultura gallegues.

Paraules clau: Iberisme, Joan Estelrich, Oficina d'Expansió Catalana.

\begin{abstract}
In the first decades of the 20th century, magazines written in the different peninsular languages were published. That was the case of La Gaceta Literaria in which it was common to read articles both in Catalan and Portuguese. These multilingual publications coincided with the Golden Age of Galician journalism, and not only did they maintain the Iberism as the new territorial paradigm, but they also provided a cultural stabilization for a new Spain. A regional, cultural and linguistic utopia was built by a series of articles shared among the different peninsular nations. In this respect, in the article I am about to present, we will see how the Lliga Regionalista had a strong influence on the press and on the Galician culture.
\end{abstract}

Keywords: Iberism, Joan Estelrich, Oficina d'Expansió Catalana. 
A Antonio Villar Ponte en este dia consagrador de las libertades catalanas, preludio de las libertades gallegas, con el fervoroso homenaje de admiración de su devoto

J. Estelrich. S. Sebastian 15/IX/1932

L'any 1949 Joan Estelrich (Felanitx, 1896-París, 1958) publicà La Falsa $\mathrm{Paz}$, on explica que la major part de les pàgines que integren el llibre es van escriure durant els anys 1946 i 1947, «cuando la "falsa paz" fue tomando su agrio e inquietante cariz» (1949: 12). Aquest pessimisme d'Estelrich envers les restes del naufragi de la Segona Guerra Mundial es contradeia amb l'optimisme que ell mateix va tenir quan dirigia l'Oficina d'Expansió Catalana, lobby propagandístic catalanista constituït el 1919 que aprofitava les esperances d'autodeterminació suscitades pels punts de Wilson. ${ }^{2}$ L'Oficina d'Expansió Catalana va dur a terme una gran tasca en la divulgació de la cultura catalana a l'estranger ${ }^{3}$ i va internacionalitzar el conflicte català segons el model de les campanyes dutes a terme per altres pobles europeus com Txèquia, Lituània $\mathrm{i}$ Irlanda. ${ }^{4} \mathrm{Si}$ ens endinsem en els primers projectes, en els papers privats i en la intrahistòria de l'Oficina d'Expansió Catalana podrem aprofundir en l'estudi de qüestions cabdals de la vida i l'obra d'Estelrich, com la construcció de les posicions polítiques, tàctiques i estratègiques en què l'intel-lectual va prendre part $i$ les decisions i els projectes que no es van poder dur a terme. Un d'aquests projectes realitzats fou la creació de fluxos i ponts intel-lectuals entre Galícia i Catalunya, ja fos com a preludi de les futures relacions luso-catalanes, ja fos com a lògica conseqüència de les intenses estratègies que dugueren l'Oficina d'Expansió Catalana a bastir ponts entre Portugal i Catalunya. Aquests contactes caldria encabir-los en l'ambiciós projecte de trencar el monopoli castellanocèntric $\mathrm{i}$ virar cap a un multilateralisme peninsular. $\mathrm{O}$ el que és el mateix, l'iberisme catalanista ${ }^{5}$ incloïa Portugal dins el marc geopolític espanyol (i es creava així Ibèria) per tal de diluir el pes específic del centre de la península.

1 Dedicatòria de l'exemplar de Catalunya i Reforma hispánica (1932) de Joan Estelrich dipositat a la Biblioteca da Real Academia Galega (A Coruña), en què l'autor celebra la signatura de l'Estatut de Catalunya.

2 Respecte dels punts de Wilson, Bartomeu Carrió, en parlar sobre el pensament mallorquinista, considera que, «en aquest pensament, hi veim la influència de les doctrines wilsonianes, tan importants a l'Europa de la Primera Guerra Mundial. A més, i com una constant a través del temps, Estelrich, com la majoria de la Lliga i dels nacionalistes mallorquins conservadors i de l'esquerra, sempre propugna solucions federals, regionalistes o autonòmiques, tant a Espanya com a qualsevol estat d'Europa» (1997: 60).

3 Com explica Enric Ucelay Da-Cal, «tal proyección hacia fuera, como «imperialismo cultural», resolvería — creía el líder de la Lliga — las envidias mutuas y forjaría un futuro común que preservaría la herencia catalana y modernizaría la castellana» (2003: 829-830).

4 Ho expliquen Gavagnin (2005: 135-136) i Corretger (2008: 99-125).

5 Els treballs de Víctor Martínez-Gil sobre l'«iberisme catalanista» són extensos i precisos. Vegeu, per exemple, Martínez-Gil 1997 i 2000, en què defineix aquest iberisme com «un nacionalisme aglutinador basat en l'existència al llarg de la història d'un sentiment de peninsularitat geogràfica i cultural» (2000: 149). Sobre les relacions entre Catalunya i Portugal, vegeu també Martínez-Gil (2010). 
Francesc Cambó i el nacionalisme català proposà una mena de zollverein peninsular ${ }^{6}$ ja fos com a causa o com a conseqüència de l'iberisme. Aquesta fixació per Portugal arriba a la mà dreta de Cambó, ${ }^{7}$ el felanitxer Joan Estelrich, que ja l'any 1919 havia viatjat amb Eugeni d'Ors a Portugal. ${ }^{8}$ L'Oficina d'Expansió Catalana lligà imperialisme cultural i econòmic quan, per posar un cas, Estelrich, gràcies a la plataforma de contactes lusitans, va pretendre establir relacions econòmiques amb la Sociedad Agrícola Industrial d'Angola. El felanitxer considerava que la riquesa catalana podia tenir una gran influència a les possessions portugueses d'Âfrica amb una companyia finançada pels industrials tèxtils d'ambdós països.

Entre la documentació del fons Joan Estelrich (dipositada a la Biblioteca de Catalunya i en procés d'ordenació) podem trobar part de la correspondència amb personalitats portugueses. Estelrich, a la seva memòria sobre les tasques d'Expansió Catalana durant l'estiu de 1921, escriu el següent:

El nostre esforç s'ha dirigit a estudiar les possibilitats portugueses, a establir correspondència constant amb els principals politics, publicistes i professors, a posar en relació els portuguesos i els gallegs, a practicar totes les formes d'intercanvi amb Portugal [...]. En aquest aspecte de l'Expansió si que estem satisfets en absolut de la nostra tasca. Sols esmentarem dos fets recentissims: la visita gloriosa d'alguns eminents portuguesos a Galicia, fruit de la nostra acció intermediaria; L'Exposició d'Art Català que el vinent novembre es celebrarà a Lisboa i la Setmana Catalana.

Si mirem la documentació d'Estelrich cal destacar la gran quantitat d'articles creuats. Podem trobar notes, retalls de premsa, fragments de discursos, articles que donen notícies del mateix viatge, $i$ articles que es van gestar a partir dels contactes duts a terme en el mateix viatge. Si llegim aquesta documentació trobarem referències contínues als importants enllaços culturals d'Estelrich a Portugal:

L'il·lustre professor lusità Leonardo Coimbra ${ }^{9}$ està disposat a venir a donar un curs de lliçons que organitza l'Institut d'Estudis Catalans, o bé el Consell de

6 És el cas del mercat surer i de la posada en funcionament d'una Lliga Aduanera HispanoPortuguesa que havia d'evitar l'exportació de matèria primera.

7 A la biblioteca de la Fundació Francesc Cambó (Barcelona) podem trobar diferents llibres de temàtica iberista, com La unión ibérica (1914), de Juan del Nido y Segalerva; El problema peninsular (1933), de Joaquim Cases-Carbó; o Un llibre estel de Joaquim Cases-Carbó «El problema peninsular» (1935), de Francesc Pujols, amb la següent dedicatòria: «a Francesc Cambó, el gran activador de l'unitat iberica». Portugal fou utilitzat per Cambó a Per la concòrdia (1930) per mitigar el radicalisme català amb l'argument que, encara que el país lusità era independent, més gran i amb un imperi colonial, no havia de ser envejat pels catalans. He tractat amb més profunditat aquesta qüestió a Revelles (2010).

8 Sobre la visita d'Ors i Estelrich a Portugal, vegeu Cerdà (2000).

9 Leonardo Coimbra (1883-1936) fou un dels fundadors de la Renascença Portuguesa. Va exercir de professor de Filosofia de la Faculdade de Letras do Porto i, el juny de 1919, visità Barcelona, convidat per Eugeni d'Ors, per impartir un curs sobre «El Pensamiento Portugués Moderno». 
Pedagogia de la Mancomunitat, Leonardo Coimbra, Teixeira de Pascoaes, Pina de Morais $^{10}$ i altres intensifiquen la campanya d'aproximació als nacionalistes gallecs, els quals reben molt bé aquestes activitats que nosaltres sugerirem. Aquesta darrera primavera i estiu han realitzat excursions per Galicia amb un èxit insospitable.

L'escriptor considera que les revistes conservadores i les agències de notícies de Madrid distorsionen dues realitats socials i polítiques: les de Catalunya i Portugal. Però, què proposa Estelrich per tal de contrarestar la propaganda de descrèdit? Doncs una oficina catalana de propaganda exterior, una mena de seu de l'Oficina d'Expansió Catalana establerta a Lisboa. Tanmateix, finalment aquesta idea no prosperà.

A la memòria documental d'Estelrich podem trobar un text titulat «Les valors portugueses d'avui», en què l'intel-lectual presenta una enquesta realitzada a un sanedrí portuguès: Leonardo Coimbra, Teixeira de Pascoaes, Augusto Casimiro, ${ }^{11}$ Jaime Cortesão ${ }^{12}$ i Pina de Morais, entre d'altres. Aquests articles es publiquen finalment a La Publicidad sota l'epígraf «Cartas lusitanas». Es tracta d'un seguit de biografies breus, que Estelrich confeccionà a partir de tots els contactes que féu a Portugal ${ }^{13}$ i que signa com a «enviado especial».

Estelrich, sempre amb un ull a la península però amb un altre en l'àmbit internacional, adjunta, en el dossier amb documentació de l'Oficina d'Expansió Catalana, dos articles de dues capçaleres internacionals d'allò més prestigioses: ${ }^{14}$ The Times Literary Supplement i Mercure de la France.

El felanitxer organitzà un tràfic d'articles traduïts entre Portugal i Catalunya... amb parada a Galícia. La geopolítica cultural necessitava d'un tercer

10 João Pina de Morais (1889-1953) fou un escriptor, periodista, polític i militar portuguès. Col-laborà a la publicació Seara Nova.

11 Augusto Casimiro (1889-1967), poeta, periodista i opositor a l'Estado Novo, fou un dels fundadors de Renascença Portuguesa (1912) i de Seara Nova (el primer número de la qual es publicà el 15 d'octubre de 1921). Aquesta darrera revista, que Casimiro dirigí entre l'any 1961 i el 1967, havia sorgit de l'escissió del grup de la «Renascença Portuguesa». Perfecto Cuadrado explica el següent: «Los hombres de Seara Nova pretendían oponer un pensamiento racionalista de corte neopositivista y un programa político republicano radical al irracionalismo y misticismo saudosista-creacionista y al nacionalismo de corte para-fascista que se había impuesto en el seno de la "Renascença Portuguesa"» (2007: 226).

12 Jaime Cortesão (1884-1960) fou poeta, dramaturg, historiador i director de la Biblioteca Nacional de Portugal.

13 A la Memòria hi trobem les «Cartas lusitanas» dedicades a Leonardo Coimbra (30/ IX/1920, edició matí, p. 6); Teixeira de Pascoaes (6/X/1920, edició matí, p. 1); Pina de Morais (14/X/1920, edició matí, p. 1); Jaime Cortesão (20/XI/1920, edició matí, p. 1); i Augusto Casimiro (26/XI/1920, edició matí, p. 1).

${ }_{14}$ A The Times Literary Supplement podem llegir («Portugal y el hispanismo», 17/IX/1920, p. 605) una carta al director de l'escriptora Annette M. B. Meakin, en què recorda la seva assistència a una reunió de la Real Academia Galega on es va admetre com a membre el poeta Ramon Cabanillas. El segon article (Mercure de la France, 15/II/1921, p. 261-266) és del conegut poeta, crític literari i lusitanista francès Philéas Lebesgue. 
element. Catalunya necessita l'ajuda d'una altra nació que, de manera interessada però també generosa, s'impliqui en la seva reconfiguració nacional. Així, demana a Portugal que torni el favor històric de la seva independència amb una defensa ferma dels drets de Catalunya. A Galícia, en canvi, li demana que ajudi a reequilibrar la correspondència de forces dins la península. És per això que entre els documents d'Estelrich trobem un capítol titulat «L'aproximació lusogalaica».

L'aproximació luso-galaica fou un dels aspectes de la nostra missió en què més insistirem. La propaganda per l'intercanvi luso-galaic estava totalment inèdita. De l'octubre ençà s'és fet molt de camí. En aquest punt, estem satisfectissims del bell resultat immediat de les gestions nostres. Bé és veritat que per tot les nostres insinuacions trobaren bonissima acullida. Tothom es disposà a iniciar la campanya: professors, premsa, literats, poetes, militars.

La comitiva catalana vincula la sort de Portugal amb la de Galícia a causa d'aquesta reformulació peninsular. De fet, és justament entre 1918 i 1923 quan hi ha un apropament més profund entre Galícia i Portugal. Estelrich apostà per una aproximació luso-galaica ben reeixida: «Manca a Portugal el seu essencial complement: Galicia. La unió amb Galícia li pot resoldre moltes qüestions vitalíssimes: unitat espiritual, major potència econòmica, augment d'efectius humans, bons elements de colonització, desaparició dels conflictes de pesca, etc.» (1920b: 13). Així, serà Leonardo Coimbra (recordem que havia estat ministre d'Educació de la República portuguesa i un dels fundadors de la Universidade do Porto) el més procliu als contactes amb intel-lectuals galleguistes. ${ }^{15}$

Un dels primers actes que projectàrem fou invitar a significats poetes i literats galleguistes perque anessi al Porto, on seràn rebuts amb gran entusiasme. La nova agrupació s'ha d'ocupar tambè, en segón terme, de l'intercanvi lusocatalà. La propaganda iniciada va congriant-se en belles realitats, com veurem pels documents que reproduïm a continuació. Estem tambè en relació constant amb els capdevanters del nacionalisme galleg: Vicens Risco i la revista Nós ${ }^{16}$ d'Ourens; Villar-Ponte i A Nossa Terra de la Coruña. No cal ja instar-nos; el moviment d'aproximació iniciat ferà el seu fet sense més impulsos. Es un moviment fatal.

En aquestes primeres dècades del segle xx transcorre l'etapa inicial d'un galleguisme ja articulat i protagonitzat en molts casos per membres del sistema educatiu. A final de la primera dècada i principi dels anys vint l'aproximació Portugal-Galícia és recíproca. El grup Nós (Vicente Risco, Otero Pedrayo, Castelao) manifesta una gran simpatia per Portugal. ${ }^{17}$ Aquest grup galleguista - des de la revista Nós - intenta una aproximació al grup cultural més important

\footnotetext{
15 Leonardo Coimbra visità A Coruña el mes de setembre de 1921.

16 Sobre Risco, la revista Nós i Portugal, vegeu Harrington (2001), Valiente Fernández (2007).

17 Vegeu Santos Araújo (2004: 109-134).
} 
d'aleshores a Portugal, Renascença, el qual tenia com a òrgan la revista saudosista A Águia. En aquest grup hi col-laboraven Raul Brandão, ${ }^{18}$ Leonardo Coimbra y Teixeira de Pascoaes. ${ }^{19}$

L'any 1918 es va celebrar a Lugo la 1a Assemblea Nacionalista, en la qual es va acordar lluitar per l'oficialització del gallec i per una organització d'Espanya federal. El pangalleguisme de Villar Ponte comportava la federació ibèrica i conseqüentment una identitat luso-galaica. Per als gallecs, Portugal esdevé l'única manera de sortir de l'opressió castellana. Vicente Risco publica Teoria do Nacionalismo Galego (1920), un llibre influit per Teixeira de Pascoaes i pel saudosime ibèric comú, que mostra, per exemple, a Arte de ser portugués (1915).

El mateix Pascoaes escriu el dimarts 13 de juliol de 1920 un article a $L a$ Vanguardia titulat «Saudade y quijotismo», en què, entre d'altres coses, escriu: «Como buen portugués es justo que consagre a la saudade las primeras palabras que le dirijo. Mas la saudade ¿es extranjera en Cataluña? La saudade ciñe casi toda la Iberia en un abrazo, como las brumas del mar [...]. La saudade es portuguesa como es gallega y catalana» (1920: 12).

Risco — que va apropar les grafies gallega i portuguesa— proposà una campanya de propaganda cultural prèvia a una activitat política que calcava l'estratègia d'Estelrich i de la Lliga. Ribera Llopis (1998: 97) veu els paral-lelismes i les coincidències entre les dues estratègies nacionalistes, sobretot els interessos anticentralistes entre Solidaridade Gallega i la Lliga. Risco proposà l'atlantisme (també comú a Ribera i Rovira) ${ }^{20}$ com a teologia del nacionalisme i com a missió històrica tant de Galícia com de Portugal, dues nacions que protagonitzaran el futur.

A La Revista, sota el títol de «La Civilització Atlàntica», podem llegir el següent: «Aquest pressentiment de la Civilització Atlàntica esdevé una forta preocupació en la intel-lectualitat gallega. Les joventuts celtes recerquen la personalitat viva de la Pàtria. Són optimistes i enfront de l'Europa envellida creuen en les possibilitats creadores dels vells pobles opressors» (S. A. 1920a). En la mateixa publicació, i mesos més tard, s'hi inclogué l'article «La Teleologia del nacionalisme gallec», en què es parla de la civilització atlàntica i es

18 Raul Brandão (1867-1930) és l'autor d'Hummus (1917), una de les obres fundacionals de la modernitat portuguesa. Ribera i Rovira, que la traduí al castellà, inclou Brandão a la seva antologia Contistes portuguesos (1913).

19 Pascoaes, l'any 1918 va dictar a l'Ateneu Barcelonès la conferència «Els aspectes sentimentals en la història de la poesia portuguesa», inclosa en els «Cursos Monogràfics d'Alts Estudis i d'Intercanvi» organitzats per l'Institut d'Estudis Catalans. En aquestes conferències a Barcelona — part de les quals es compilaren posteriorment al llibre Os Poetas Lusíadas - Pascoaes parla del seu ideal de la federació espiritual ibèrica, basada en la saudade.

20 Ribera i Rovira, que va tenir contactes amb la «Renascença Portuguesa» fins al punt de ser el corresponsal d'A Águia, considera comuna la pàtria gallega i la portugesa. A Portugal y Galicia nación (1911) titulà el primer capítol «La unidad atlántica peninsular». De fet, A Nosa Terra publicà a la seva coberta del 10 de maig de 1918 «Ibeirismo atlántico»; recull de fragments del seu llibre «Iberisme» (1907). 
citen llargs paràgrafs del volum Teoría do Nacionalismo Galego traduït al català (S. A. 1920c).

En els papers d'Estelrich hi ha referències a les revistes: Nós i A Nossa Terra.

Nós neix el 30 d'octubre de 1920. Els fundadors d'aquesta publicació foren Vicente Risco, Ramón Otero Pedrayo, Florentino López Cuevillas, Antón Lousada Diéguez i Castelao. Nós pretenia bastir ponts entre Galícia i Portugal. ${ }^{21}$ El corresponsal de la revista a Barcelona fou Tomàs Garcés, ${ }^{22}$ i a França, Philéas Lebesgue. De fet, a tots els números de Nós podem trobar la secció «Os homes, os feitos, as verbas», on es publiquen notes de revistes que, en la majoria dels casos, són revistes escrites en català, com El Día, La Revista, Proa, L'amic de les arts. ${ }^{23}$

Per la seva banda, A Nosa Terra era l'òrgan propagandístic de les Irmandades da Fala, fundades l'any 1916 per un bon grup d'intel-lectuals com Antonio Villar Ponte, Ramón Villar Ponte, Viqueira, Peña Novo, Losada Diéguez i Risco. A A Nosa Terra, Estelrich escriu «A esencia do problema catalán» (1920a: 1). L'article es clou amb les següents paraules: «Hoxe escomenza un intertroque d'artigos culturaes entre "A Nosa Terra" e "La Revista" de Barcelona».

Així, s'explicita l'acord per publicar articles en català traduïts al gallec i enviar articles en gallec que es traduiran en català. Estelrich escampa aquest trànsit d'articles no només entre Portugal i Catalunya, sinó que hi inclou, i això torna a remetre'ns al tercer estat, al galleguisme.

Pel que fa a aquest tràfic, vegem com es parla de l'Homenatge al soldat portuguès als textos «As homenagens de um jornal de Catalunha» (Diario de Noticias, 20 d'abril de 1921, p. 1) i «Lisboa e Barcelona: Homenagem de "La Veu de Catalunya" a Portugal» (Diario de Lisboa, 14 d'abril de 1921, p. 2). Ambdós articles fan referència a «L'homenatge de Portugal» (La Veu de Catalunya, 8 d'abril de 1921, p. 8). En aquest darrer article podem llegir el següent: «Aquestes festes portugueses ens recorden un motiu més de germanor entre Lusitània i Catalunya. Durant els dies inoblidables de la guerra gran, mentre la nissaga humana escrivia amb sang un dels més formidables capítols de la història universal, els pobles d'Ibèria esdevenien representats als camps de batalla d'Europa per l'exèrcit portuguès i els voluntaris catalans».

Els primers contactes entre las Irmandades i el catalanisme daten de l'any 1917, durant els preparatius d'una visita a Galícia que havien de fer els líders catalans el gener de 1917 i que finalment no es dugué a terme. En aquestes mateixes dates Cambó defensà al Congrés dels diputats espanyol interessos ferroviaris amb la construcció de la línia «Ponferrada-Villabino» fins al punt

\footnotetext{
21 Sobre les relacions entre Galícia i Portugal, vegeu Villares (2003), Medeiros (2006).

22 La revista Nós (núm. 3, 3/XII/1920, p. 14) reprodueix un article de Tomàs Garcés a la secció «Letres catalanes» titulat «Àngel Guimerà, poeta»

23 A més, Nós publica referències elogioses a dos llibres d'Estelrich: La Qüestió de les minories nacionals (núm. 70, 15/X/1929, p. 184) i Catalunya Endins (núm. 83, 15/XI/1930, p. 229).
} 
que l'empresa ferroviària va batejar amb el nom de Francisco Cambó la primera locomotora del trajecte. Així, el mes de setembre de 1917 Cambó visità Galícia i es reuní amb Antón Villar Ponte i Rodrigo Sanz. El novembre, una comitiva galleguista tornà la visita i viatjà a Catalunya. ${ }^{24}$ En aquestes reunions Cambó fa confiança en Villar Ponte i l'autoritza per comprar la capçalera del diari $E l$ Noroeste. El desembre següent, Cambó torna a visitar Galícia i pronuncia mítings a A Coruña, Santiago i Ourense. La Lliga s'adona que la seva aposta per Galícia, per federar Espanya i per tenir una porta oberta amb Portugal és una aposta sòlida. I és en aquest sentit que cal ponderar un fet tan arriscat com comprar el diari gallec El Noroeste..$^{25}$ La nova propietat, sota la direcció d'Antón Villar Ponte, s'inicià a principi de febrer i finalitzà el mes d'agost d'aquell mateix any.

El febrer de 1918 es convocaren eleccions parlamentàries a Galícia. Les Irmandades es presentaren a tres districtes i no aconseguiren obtenir cap diputat, fet que suposà un refredament de l'estratègia de la Lliga.

Als papers privats d'Estelrich també es pot trobar un document mecanografiat que porta per títol «El problema dels pobles peninsulars». És un text que Estelrich va fer traduir al portuguès i que es va repartir sota el títol $\mathrm{d}^{\prime} \ll \mathrm{O}$ problema dos povos peninsulares do ponto de vista português e catalão». A continuació, en reproduïm alguns fragments:

\section{EL PROBLEMA DELS POBLES PENINSULARS}

Pensamos nós que falta a Portugal um complemento essencial: A Galiza. A união com a Galiza poderia resolver muitos problemas: unidade espiritual, potência económica, aumento de efectivos/ recursos humanos, elementos de colonização, conflitos de pesca.

Se Portugal centrar a sua perspectiva em direcção ao futuro, não pode deixar de orientar a sua política na direcção dum estado galaico-português. Mas Espanha, que forte, não consentir o desmembramento e não fácil, por agora, que os galegos, apesar de toda a propaganda o consintam, também. O problema galaico-português, não pode resolver-se isoladamente sem que se verifique o fracasso de alguma das partes. É que o problema galaico-português um aspecto do problema dos povos peninsulares.

Tem-se feito muita propaganda, sobretudo nos meios centralistas de Madrid e nos conservadores de Portugal para uma união entre Portugal e Espanha. Mas não de crer que Portugal caia na (esparrela) cilada. A Espanha actual, com a

\footnotetext{
${ }^{24}$ La comitiva estava formada per Rodrigo Sanz, Aurelio Ribalta, Manoel Banet Fontenla, Lois Peña Novo, Lois Porteiro, Antonio e Ramón Villar Ponte, Antonio Losada, Leandro Pita Romero, Antonio Valcárcel e Franciso Vázquez Enríquez.

25 «Segundo Diario de Galicia de Santiago (31-1-1918) "los catalanistas" adquiriran o xornal por 160.000 ptas. e Pere Muntanyola instalaríase na Coruña para administralo» (Beramendi 2008: 454).
} 
Catalunha oprimida e a Galiza castelhanizada, não pode oferecer, pensamos nós, nenhuma garantia a Portugal.

$[\ldots]$

Apresentados assim os termos do problema que, a nosso ver, são os mais realistas, põe-se uma questão prévia: a necessidade de se produzirem entre Portugal e a Galiza e entre Portugal e a Catalunha fortes correntes de simpatia e de acordo/ consenso espiritual começando pelos mais íntimos relacionamentos intelectuais, estabelecendo-se depois generosas relações políticas, e acabando em propaganda populares, que têm $\mathrm{j}$ uma forte base no sentimento espontâneo dos dois povos.

L'article es fa arribar no només als contactes portuguesos, sinó també a càrrecs polítics. El resultat dels contactes polítics fou la negativa del govern portuguès a fomentar l'independentisme gallec. Així i tot, des del govern lusità es veu amb bons ulls qualsevol tipus d'intercanvi, ja sigui amb Galícia, ja sigui amb Catalunya. Finalment, Estelrich introdueix algun dels seus contactes amb una petita entrada enciclopèdica. Vegem-ne un exemple:

Joao Camõesas: [...] Es mostrà completament d'acord amb els nostres punts de vista; per amb un criteri molt esquerrà; està enteradissim del problema en sos detalls i es declarà partidari de les nostres solucions. Té relacions amb el socialisme espanyol i indirectament amb el nacionalisme galleg; cal fomentarlo ens digué.

Acte seguit Estelrich inclou un qüestionari titulat «La opinió portuguesa actual». Es tracta de les preguntes que es fan arribar a aquests contactes, en les quals els demanen, entre altres coses, quin els sembla el sistema polític més adient per respectar l'autonomia de tots els pobles peninsulars. El primer punt d'aquest qüestionari té com a escenari Galícia, ja que es demana sobre l'aproximació «espiritual» cap a Portugal que porta a terme el nacionalisme gallec.

Els papers privats d'Estelrich no contenen les respostes d'aquests qüestionaris. ${ }^{26}$ Aix i tot, podem tenir alguna idea de les respostes que es degueren donar si atenem el fet següent. Estelrich aconsegueix que les respostes de Machado dos Santos $^{27}$ i Augusto Casimiro apareguin publicades en forma d'articles firmats per Estelrich a La Veu de Catalunya. Les reflexions sobre la pregunta I són diverses. Llegim, per exemple, la resposta d'Augusto Casimiro a un article amb un títol tan explícit com «Catalunya = Galícia = Portugal.

\footnotetext{
26 A la revista Monitor (Any III, núm. 1, gener 1923) s'inclou un qüestionari catalano-portuguès amb deu preguntes.

27 Machado dos Santos (1875-1921) va ser militar i polític. Fou ministre d'Interior al primer govern de Sidónio Pais (1917). Morí assassinat a la Noite sangrenta (19/X/1921). L'article (signat per Estelrich) amb les seves respostes porta per títol «Lusitània-Catalunya (El que diu Machado dos Santos)» (9/XII/1920, edició matí, p. 11).
} 
(Resultats d'una enquesta)»: «Avui, les animes que escolten la veu de Galicia, les ànimes de Portugal, s'enterneixen de fraterna pietat».

Pina de Morais escriu, a Primeiro de Janeiro de 12 de novembre de 1920, l'article «Portugal na Penisula. Galiza-Catalunha-Portugal», que Estelrich fa traduir i reproduir a la secció «Catalunya enfora» de La Publicidad de 14 de febrer de 1921. Entre d'altres coses, en aquest article hi podem llegir el següent: «"el pangalleguisme" i el "catalanisme" són els únics aspectes de fer viable el problema ibéric per a nosaltres portuguesos» (Morais 1921).

En una direcció semblant, a La Revista podem llegir el breu «A Nosa Terra i Catalunya»:

Constantment, els nacionalistes gallecs estan donant prova de la llur comprensió i cordialitat. Mentre els espanyols adopten postures tràgiques, els gallecs fan sentir la llur veu fraterna i veuen amb una adhesió activa les nostres aspiracions d'independència. I així $A$ Nosa Terra ha dit: «Nosaltres preferim els catalans que senten la llur terra, a tots els polítics, cacics i homes mansos de les altres regions, que pel que veiem han nascut per destorb de la civilització» [...] Cal, doncs, que el nostre reconeixement respongui a la veu amiga d'aquella terra opresa (1920b).

Aquest treball ofereix, doncs, una nova visió de l'acció política d'Estelrich i aportarà un gra d'arena més perquè algun dia es pugui fer una teoria general sobre les relacions de l'escriptor felanitxer amb les diferents cultures i tradicions peninsulars per tal d'estudiar què aporta cada una d'aquestes en la construcció de la seva política i de la seva poètica. En certa manera, ens veiem obligats a repensar els sistemes i els camps literaris per tal d'emmarcar-los, de cada vegada més, en un àmbit cultural ibèric. Com el mateix Estelrich va citar a Catalunya Endins: «Never explain, never complain».

\section{BIBLIOGRAFIA}

Beramendi, J. G. (2008) De Provincia a Nación. Historia do Galeguismo político, Vigo, Xerais.

Cambó, F. (1930) Per la concòrdia, Barcelona, Biblioteca de Lliga Catalana / Llibreria Catalònia.

Carrió, B. (1997) «Joan Estelrich i Artigues a La Veu de Mallorca (1917)», Diversos autors, Miscel-lània Joan Estelrich, Palma, El Tall, pp. 49-82.

Casimiro, A. (1921) «Catalunya = Galícia = Portugal. (Resultats d'una enquesta)», La Veu de Catalunya, 7 de febrer (ed. vespre), p. 7.

Cerdà, J. (2000) «Eugenio d'Ors y Portugal», Carrasco González, J. M. + Fernández García, M. J. + Madeira Leal, M. L. T. (ed.), Actas del Congreso Internacional de Historia y Cultura en la Frontera - ler Encuentro de Lusitanistas Españoles, tomo 1, Cáceres, Universidad de Extremadura. 
Corretger, M. (2008) Escriptors, periodistes i crítics. El combat per la novel.la (1924-1936), Barcelona, Publicacions de l'Abadia de Montserrat.

Cuadrado, P. E. (2007) Un capítulo de la historia de las relaciones hispanoportuguesas: la revista Seara Nova, Vicens Pujol, C. (ed.) Au bout du bras du fleuve, Palma, Universitat de les Illes Balears, pp. 223-236.

Estelrich, J. (1919) «Lletres lusitanes. El viatge d'Eugeni d'Ors a Portugal Camí de Lisboa», La Veu de Catalunya, 1 de juliol, p. 7.

- (1920a) «A esencia do problema catalán», A Nosa Terra, núm. 118, 25 d'abril, p. 1.

- (1920b) «Per l'aproximació luso-catalana», Butlletí de les Joventuts Nacionalistes de Catalunya, any 1, núm. 3 (Nadal), pp. 13-15.

- (1949) La Falsa Paz, Barcelona, Llibreria Catalònia.

Gavagnin, G. (2005) Classicisme i Renaixement, una idea d'Itàlia durant el Noucentisme, Barcelona, Publicacions de l'Abadia de Montserrat.

Harrington, T. S. (2001) «Risco y Portugal: Contactos anteriores a la época de Teoría do nacionalismo galego y la revista Nós», Revista de Lenguas y Literaturas Catalana, Gallega y Vasca, 7 (2001), pp. 247-262.

Martínez-Gil, V. (1997) El naixement de l'iberisme catalanista, Barcelona, Curial.

- (2000) «L'iberisme català i la crisi colonial dels estats peninsulars», DD. AA. 1898: Entre la crisi d'identitat i la modernització, Barcelona, Publicacions de l'Abadia de Montserrat, pp. 149-160.

Martínez-Gil, V. (ed.) (2010) «Uns apartats germans»: Portugal i Catalunya / «Irmãos afastados»: Portugal e a Catalunha, Palma, Lleonard Muntaner, Editor, pp. 149-168.

Medeiros, A. (2006) «Los dos lados de un río», Nacionalismos y etnografías en Portugal y en Galicia, Madrid, CIS / Siglo XXI.

Morais, P. de (1921) «Galiza-Catalunha-Portugal», La Publicidad, 14 de febrer, p. 2.

Pascoaes, T. de (1920) «Saudade y quijotismo», La Vanguardia, 13 de juliol, p. 12.

Revelles, J. (2010) «Cambó, Pla, Gaziel i els contactes lusocatalans», MartínezGil, V. (ed.), «Uns apartats germans»: Portugal i Catalunya / «Irmãos afastados»: Portugal e a Catalunha, Palma, Lleonard Muntaner, Editor, pp. 149-168.

Ribera Llopis, J. M. + Rodríguez González, O. (1998) «Aproximación ás relacións literarias galego-catalans. Noticias históricas e bibliográficas», Madrygal, 1, Servicios de Publicaciones, Universidad Complutense, pp. 97-100. 
- (2000-2001) «Relaciones literarias gallego-catalanas (1920-1939): Materiales y propuestas para su estudio», Revista de lenguas y literatures catalana, gallega y vasca, núm. 7 (1 de setembre), pp. 121-130.

S. A. (1920a) «La Civilització Atlàntica», La Revista, Any VI, Núm. 112, 16 de maig, p. 4.

S. A. (1920b) «A Nosa Terra i Catalunya» La Revista, Any VI, Núm. 115, 1 de juliol, p. 183.

S. A. (1920c) «La Teleologia del nacionalisme gallec», La Revista, Any VI, Núm. 116, 16 de juliol, pp. 197-198.

S. A. (1921) «L'homenatge de Portugal», La Veu de Catalunya, 8 d'abril, p. 8.

Santos Araújo, J. D. (2004) Portugal e Galiza. Encantos e encontros, Santiago de Compostela, Edicións Laiovento.

Ucelay-Da Cal, E. (2003) El imperialismo catalán: Prat de la Riba, Cambó, D'Ors y la conquista moral de España, Barcelona, Edhasa.

Valiente Fernández, A. (2007) «La recepción de la cultura portuguesa en la revista Nós», Revista de Filología Románica, vol. 24, pp. 251-262.

Villares, R. (2003) «Portugal, Galicia e o iberismo», DD. AA. Galiza e Portugal: identidades e fronteiras, Santiago de Compostela, Universidad de Santiago de Compostela, pp. 13-28. 